\title{
A Gestante Adolescente e seu Parceiro: Características do Relacionamento do Casal e Aceitação da Gravidez
}

Autor: Alberto Mantovani Abeche

Orientador: Prof.Dr. Edison Capp

Dissertação de Mestrado apresentada ao Programa de Pós Graduação em Medicina: Departamento de Clínica Médica - Faculdade de Medicina da Universidade Federal do Rio Grande do Sul, em 15 de outubro de 2002.

Objetivos: avaliar as características da gestante e seu parceiro, planejamento desta gestação e a forma pela qual foi recebida pelo casal, correlacionando estes dados com o fato deste ser ou não o primeiro parceiro da adolescente e com a situação de morarem juntos.

Métodos: neste estudo transversal foram entrevistadas 309 gestantes com idade entre 11 e 19 anos, aplicando-se um questionário padronizado abordando características da gestante adolescente e seu parceiro, aceitação e intencionalidade da gravidez atual. Utilizou-se o teste $t$ de Student e o teste exato de Fisher para a análise estatística.

Resultados: os parceiros das gestantes adolescentes apresentaram, em média, idade 4 anos superior à delas. A gestação foi planejada em $22 \%$ dos casos. $61,1 \%$ das pacientes engravidaram de primeiros parceiros e $53,4 \%$ dos casais moravam juntos no momento da en- trevista. Houve melhor aceitação da gravidez no grupo de pacientes que engravidaram de primeiros parceiros (84,1\% x 69\% - p: 0,003). Quando a paciente e seu parceiro moravam juntos, observou-se maior freqüência de gestações planejadas $(32,1 \% \times 10,7 \%-\mathrm{p}<0,001)$ e bem aceitas por ela $(83 \%$ x $66,4 \%$ - p<0,001) e seu companheiro $(89,7 \%$ x $64,2 \%-p<0,001)$.

Conclusões: a gestação na adolescência não é invariavelmente fruto de falha na contracepção ou na orientação anticoncepcional. Há um número expressivo de gestações planejadas ou bem recebidas pelo casal, principalmente quando se trata do primeiro parceiro da adolescente ou de casais morando juntos.

Palavras-chave: Adolescência. Gravidez normal. Planejamento familiar.

\section{RBG0 25(7):535, 2003}

Resumo de Tese

\section{Ansiedade e Depressão Associadas ao Diagnóstico de Diabetes Mellitus Gestacional}

Autora: Laise Potério dos Santos

Orientador: Prof. Dr. Belmiro Gonçalves Pereira

Dissertação de Mestrado apresentada ao Curso de Pós Graduação da Faculdade de Ciências Médicas da Universidade Estadual de Campinas para obtenção do título de Mestre,em Tocoginecologia, em 27 de junho de 2003.

O objetivo do estudo foi avaliar a ansiedade e depressão em gestantes que receberam o diagnóstico de $d i$ abetes mellitus gestacional. Foi utilizada a Escala Hospitalar de Ansiedade e Depressão. Foi um estudo-piloto qualitativo de algumas características psicológicas destas mulheres. Foram incluídas no estudo 20 gestantes que receberam o diagnóstico de diabetes mellitus gestacional, pela primeira vez, nesta gestação. Estas gestantes foram convidadas a participar do estudo, a responder um questionário específico e às perguntas da Escala Hospitalar de Ansiedade e Depressão. Algumas variáveis demográficas como idade e da história obstétrica, foram avaliadas assim como o desejo e planejamento desta gestação. Trinta e cinco por cento das gestantes diabéticas avaliadas apresentaram depressão e 30\% apresentaram ansiedade.
A concomitância de ansiedade e depressão foi observada em quatro das 20 pacientes (20\%). As demais variáveis analisadas, como desejo ou planejamento da gravidez pela gestante ou casal, assim como as variáveis sociodemográficas ou obstétricas, não interferiram nesta distribuição, embora mostrassem certa tendência à maior freqüência destes transtornos de humor as gestantes com maior número de gestações, gestantes cujas gestações não foram desejadas ou não planejadas. Estes dados reforçam a necessidade de se prosseguir neste estudo ampliando a casuística.

Palavras-chave: Diabete gestacional. Ansiedade. Depressão. Diabete melito. 